\title{
Developing interethnic tolerance of students in foreign language lessons
}

\author{
Yakubbayev Murodilla Marufovich ${ }^{1}$ \\ ${ }^{1}$ Namangan State University, Uzbekistan \\ Email: murodilla85@mail.ru
}

\begin{abstract}
The article discusses the problem of forming interethnic tolerance in students. The sequence of development of the model of formation of interethnic tolerance in students of nonphilological education of higher educational institution is shown. The stages of formation of interethnic tolerance, the goals and objectives of the formation of this personal quality at each stage, as well as the methods of formation of interethnic tolerance in students through the design model are highlighted.

Keywords: interethnic tolerance, students of non-philological education, foreign language lessons, model of the process of formation of interethnic tolerance.
\end{abstract}

\section{Introduction}

Today, higher education faces the task of modern-innovative education from traditional education and the creative use of ethnopedagogical methods in the educational process. The education system should be aimed at ensuring the historical continuity of generations, the preservation, dissemination and development of national culture, as well as a careful approach to the historical and cultural heritage of the Uzbek people.

Unfortunately, we encounter some students who do not know their native language, history and culture of their people, national traditions, and customs. Therefore, it is very important to acquaint students with the spiritual heritage, cultural riches, historical objects of the people, to form a constant interest in it, to awaken a sense of patriotism, to learn about the talented and wise ancestors of the native people.

The Action Strategy for the Further Development of the Republic of Uzbekistan states that "Education of physically healthy, mentally and intellectually developed, independent-minded, loyal to the Fatherland, strong outlook on life, deepening democratic reforms and increasing their social activity in the development of civil society" [The Decree of the President of the Republic, 2017] were identified as priorities. This requires the improvement of the content, principles and models of the formation of interethnic tolerance in non-philological students on the basis of anthropological approaches.

\section{Material and Method}

In 1995, the General Conference of UNESCO adopted the "Declaration of Principles of Tolerance", which, along with 185 countries, adheres to this declaration. At the same time, the declaration calls for the prevention of racial, national, linguistic and religious violence that threatens the peoples of the world, and encourages people of different nationalities to live in peace. The document emphasizes that tolerance is a virtue that allows 
peace to be achieved, allowing the culture of war to be replaced by a culture of peace. Tolerance is expressed as a form of mutual respect, understanding of the richness and diversity of national cultures, national identity and self-expression. Tolerance means abandoning bigotry, human rights and adhering to internationally recognized social norms [Saidov, A. 1999].

In the dictionary of pedagogical terms, tolerance is "Tolerance - tolerance for the lifestyle, behavior, habits, feelings, opinions, ideas and beliefs of others" [Djurayev R. 2008].

In the explanatory dictionary of the Uzbek language, "Tolerance is a broad, open approach to the issue" [Mirzaev T.]. In the Glossary of Basic Concepts of Spirituality, "Tolerance is a concept that refers to people who are kind, caring, generous, generous, and have such spiritual qualities [Sultonov Kh. 2010].

In the process of globalization, many nations enter into interactions, and this creates a need for the formation of interethnic tolerance. This means that there is a certain interdependence and relationship based on respecting, understanding, acknowledging and accepting others. At the same time, people of different nationalities and religions share spiritual values, ideas and experiences. Interethnic tolerance is understood as a multifaceted phenomenon and an active virtue of life, openness, willingness to communicate with people of different nationalities, respect for any other values, norms, lifestyle, behavior, customs, feelings, thoughts, ideas, beliefs is to reach. It is a human quality that is manifested in an understanding of the diversity of the world, respect, empathy, and the pursuit of positive interactions between different nations.

We see interethnic tolerance not only as an individual quality but also as a value orientation. It is a way to achieve the dignity of every human being, regardless of their origin, the inviolability of every individual, the humane coexistence of people of different nationalities. Interethnic tolerance is becoming an ideal, very important quality for both the modern individual and society as a whole. Orientation to respect values is an expression of a person's readiness to interact with other nations.

This helps to overcome noise, anxiety, fear, low self-esteem and ensures the development of a person's best qualities. Interethnic tolerance is a principle of human life aimed at respecting values [Judy E.U. 2008].

"Development of prenatal origin of the term" technical subjects and then do what purports to predict the implementation of the other. A modern interpretation of the design process to create a draft of the proposed facility. For the first time V.P.Bespalko designing pedagogy is running as an independent issue. It was designed to create educational projects as a pedagogical activity. His pedagogical design objects, according to the teaching process, teaching situations and educational systems, which are the object of pedagogy largest design [Bespalko V.P. 1989].

Design as a phenomenon is the activity of transforming natural phenomena into artificial objects and processes that meet human needs, as well as creating ideas about an object that does not yet exist.

While designing the process of formation of ethnic tolerance characteristics of young students are taken into account. The growth of adolescence, self-awareness, personal reflection, self-determination is characterized by a desire to expand the range of interests (L.I.Bojovich, L.S.Vygotskiy, A.V.Petrovskiy). Adolescence is the period of self-consciousness is characterized by the understanding of their individual characteristics. This teenage self to show our appreciation.

The person, his inner world becomes the object of students' deep understanding of the reality around them. It is an increase in self-awareness, appreciation of the spiritual and psychological qualities of the individual, an increase in interest in his own life, an increase in the desire to compare him with other individuals [Kruteckij V.A., Lukin N.S. 1965]. Based on this, the interethnic tolerance of students of non-philological education helps to form an original idea about themselves and representatives of different nationalities. At this age, students have a strong desire for a certain independence, self-esteem, a sharp reaction to the growing criticism of them by adults. Students should develop initiative, cheerfulness and similar qualities. Students not only friends, but also with their peers and decide cases [Kruteckij V.A., Lukin N.S. 1965]. Students conduct culture issues to be addressed. A new system for assessing the behavior and personality of an individual with a different hierarchy of ethical requirements has been developed. 
The formation of personality traits, according to a number of scholars, is a holistic process of creating a model for the formation of interethnic tolerance in students of the non-philological direction, when emotional perception, processing in the mind and the formation of a certain situation for itself occurs as a result of mental activity.

In the process of formation of interethnic tolerance as a personal quality in students, the state structure and dynamic structure of the pedagogical process are considered in a separate sequence, which allows considering the changes that lead to quantitative and qualitative changes in personality, its qualities and integrative features [Ilin V.S. 1984].

The basis of the process of formation of interethnic tolerance in students is: the use of various methods, forms, technical means (discussions, trainings, project method, problem situations, action games, etc.) as a tool included in the system of integrated personal development;

the use of knowledge and the formation of skills and relationships that ensure positive interactions with people of different nationalities in different walks of life.

Designing a model of the process of formation of interethnic tolerance in students begins with consideration of the purpose of the pedagogical process. V.S.Ilin educational purposes, according to the theory of the structure of the hierarchy, the person should reflect the origin and objectives, its integration with logical and should reflect the level of development of the property [Ilin V.S. 1984].

The development of a model of the process of formation of interethnic tolerance is aimed at increasing the level of integrity and formation of interethnic tolerance in students. This is due to the specific stages of the process that lead to changes in personality traits and the complexity of the goals and means of personal development of the transition from one part to another [Serikov V.V. 1994].

\section{Results}

The process of designing the formation of interethnic tolerance in students is based on an axiological approach that helps to establish the primacy of universal values.

In terms of this approach, interethnic tolerance is part of a system of values that allows it to take shape. It is a process that regulates human relationships and is based on the assimilation of sociocultural values (empathy, help, compassion, cooperation, etc.) [Kirjakova A.V. 2011]. It is well known that each person has a unique national, social, spiritual and moral character.

The effectiveness of the axiological approach in the process of forming interethnic tolerance in students increases with the high use of the axiological potential of the individual.

Successful achievement of tolerance formation helps to solve a number of tasks:

Representatives of various ethnic relations in the field of knowledge;

This information is important for a person values, teaching self-respect and respect for the dignity of others, the ability to develop;

- students of various nationalities with a tolerant attitude to skills, as well as the skills of conflict situation;

- representatives of various ethnic groups urge strengthening the relationship between social communication skills;

- non-philological students of ethnic tolerance formation in psychological-pedagogical diagnosis to determine the effectiveness.

Inter-ethnic tolerance in the process of formation and implementation of the following requirements:

- Gradual, continuous and coherent formation of interethnic tolerance in students is provided;

- "inter-ethnic tolerance" monolithic, refers to the design and implementation of a series: the initial examination of the goals and tasks;

- the selection and design of the system to be implemented in the process of forming (ethnic tolerance characteristics of certain stages of itching and the formation of asset value, quality opportunities to use this system) -corresponding to the analysis of the results;

- the stages of the process towards the formation of ethnic tolerance of the students, reflecting the gradual change of tasks to resolve them, the conditions for achieving effective results. 
The analysis of the research literature on the issue of ethnic tolerance efficient is one of the conditions that lead to the formation of the joint activities of the students, this means allowing certain events to demonstrate the value of the relationship was significantly determine that. To do this, different forms of extracurricular activities are used, using different methods and tools. The main aspect of their relationships and behavior will contribute to the formation of ethnic tolerance.

The effectiveness of collaborative activities as a means of shaping interethnic tolerance depends on students 'attitudes toward collaborative work, their planning, implementation, and final outcome. Collaborative activities allow students to engage in common work, to alleviate interpersonal conflict in relationships between young people, to identify the specific characteristics of each student, problems in relationships, behaviors.

\section{Discussion}

The stages of the process of forming interethnic tolerance in students require the implementation of goals and objectives, properly selected tools needed to address specific goals or objectives.

1. The introductory period of the process of formation of interethnic tolerance in students is aimed at enriching students' personal experience, revealing the essence of interethnic tolerance, the peculiarities of the diversity of interethnic relations in the world and the problems of relations between different nationalities.

The implementation of tasks:

$\checkmark$ to reveal the diversity and characteristics of the nations of the world;

$\checkmark$ arouse interest in the history of development of interethnic diversity in the region;

$\checkmark$ to give an idea of interethnic conflicts, their causes;

$\checkmark$ formation of a holistic view of interethnic tolerance, its types, the qualities of a tolerant person;

$\checkmark$ promote the understanding of the need to orient students to human values in choosing the form of behavior.

Teaching and learning methods are used to help students build interethnic tolerance:

- discussions, debates, that is, to inform students about the reasons for the specificity of national culture;

- trainings on perception and acceptance of "others" ("Dating", "Stepping into a circle", "Story on behalf of the national cuisine", etc.);

- gain experience through situations, trainings aimed at understanding the human values of students' daily lives;

- Games that promote a positive image of other nations in students (sports, folk games, etc.);

- Problem situations aimed at finding solutions to conflict situations in interethnic relations are identified on the basis of the analysis of psychological and pedagogical literature;

- method of comparison based on problem situations;

- joint events (organization and holding of holidays in accordance with our national traditions and customs).

As a priority form of this stage, group work of students working with elements of independent creative learning of the material on this topic is selected. This allows students to receive a variety of information not only independently, but also from classmates working in another group. It is also an opportunity for students to check and clarify their opinions and views on the events and facts under consideration, as well as to develop skills and abilities to apply existing knowledge in collaboration with non-nationals, as well as discuss topics of interest with peers.

Empirical research methods have made it possible to determine the direction of the reflex phase.

2. The reflexive stage is necessary to gain awareness of the personal significance of the concepts learned by the students;

- creating conditions for the acquisition of knowledge;

- mastering the methods of communicative communication and cooperation in multinational cooperation. 
The following tasks have been solved:

$\checkmark$ formation of respect for representatives of different interethnic groups and religions, their cultures;

$\checkmark$ to give an idea of the rules of etiquette in the interaction of different nationalities;

$\checkmark$ Development of a positive outlook in the field of relations between different nationalities (respect not only for their own nation, comparing the cultural characteristics of different peoples, solidarity with peoples, respect for national dignity).

The main tools in the formation of interethnic tolerance are debates, ideas and concepts, views. Discussions help to shape the ability to listen to others, to understand that different points of view exist, and to build confidence in the conflict of views that truth will be established. One of the important conditions of the discussion is transparency in the coverage of these negative events and analysis of their causes.

Email communication training for the development of relations with the representatives of the ethnic group the shape of the main occupations. This form of training provides an opportunity to consider the differences in different cultures, to develop the ability to use the acquired knowledge for effective interethnic communication. Developing these skills involves performing two tasks while using the exercise.

- $\quad$ The training allows students to learn about cultural or specific differences through a visual example by repeating situations that are interpreted differently by this or that cultural community.

- Training should provide a basis for analyzing the data obtained for later assimilation of knowledge in situations similar to those lost during the training [Krysin L.P, Diligenskij G.G. 2001].

Lesson development is a key component of educational content, which represents a system of knowledge, methods of work and values that ensure the development of interethnic tolerance.

The application of these methods and technologies should lead students to form qualitatively new knowledge and acquire the necessary communicative skills, accumulate and systematize intercultural communication experience, which contributes to the development of self-confidence, stimulates selfesteem and effective interethnic relations and tolerance. Should develop their competencies [Klepcova E. 2008].

3. The changing phase of the process of forming interethnic tolerance in students is aimed at increasing interethnic tolerance as a personal quality of students.

Implementing it will help solve a number of problems:

Improving their activities in mutual relations, including with other nationalities;

Actions to help resolve various conflict situations;

Organization of joint activities of youth, aimed at positive interaction of students with different nationalities.

To solve these problems, situations were chosen that represent the decision-making process in real life situations: the method of work, the use of which allowed activating knowledge in the field of the process of formation of interethnic tolerance. Discussion, participation in discussions, leads not only to the formation of a cultural discussion, but also to the spiritual and moral transformation of students.

\section{Conclusion}

Realizing that there are different perspectives, a conflict of views teaches the truth. But at the same time, you need to learn to respect your opponent and defend your point of view. It is necessary to conduct "round tables" using the project method, to develop skills and abilities of interethnic interaction between students on the basis of interethnic tolerance, to support positive experiences in the knowledge of other nationalities and to enrich the experience of personal communication.

At this stage, various action games, joint activities are actively used. During the joint activities, practical exercises and situations were used to enrich students' communication skills. 
A comparative analysis of the culture of different nations and its cultural components allows students to learn about the diversity of existing cultures, identify their economic, political and social characteristics, and learn to share the views of other ethnic cultures, as well as problems and difficulties in communicating with them allows you to overcome.

We looked at ways to shape interethnic tolerance in students. We found that all components of interethnic tolerance are closely interrelated and systemic.

Thus, the developed process of formation of interethnic tolerance was presented in the model - an artificially created environment, which regulates the use of methods that contribute to the effectiveness of this process, the goals and objectives of the process of formation of interethnic tolerance in students.

\section{References}

[1] The Decree of the President of the Republic of Uzbekistan dated February 7, 2017 "On the Strategy of actions for Further Development of the Republic of Uzbekistan” № PD-4947 // The Law of the Republic of Uzbekistan. №6 (766), Article 70 (766)]. Tashkent, 2017. Pp.25150.

[2] Saidov, A. (ed) (1999), the Declaration of principles of tolerance [Declaration about Independence adopted in the main assembly of the 28th session of the UN]. Tashkent:UNESCO.

[3] Djurayev R. (ed) Dictionary of pedagogical terms (2008) Tashkent: Fan.

[4] Mirzaev T. (ed) Definition dictionary of Uzbek language. Tashkent: National Encyclopedia of Uzbekistan.

[5] Sultonov Kh. (ed) Spirituality (2010) Cultural basis definition. Tashkent: Literature and Art Publishing House, named after G.Gulyam].

[6] Judy E.U. (2008) The forming of ethical tolerance in policulture. Siberian pedagogical magazine. No. 4. Pp. 237 - 243.

[7] Bespalko V.P. (1989) Terms pedagogical technologies. Moscow: Pedagogy.

[8] Kruteckij V.A., Lukin N.S. (1965) Psychology of adolescents. Moscow: Prosveshhenie.

[9] Ilin V.S. (1984) Forming personalities of schoolchildren. Moscow: Pedagogy.

[10] Serikov V.V. (1994) Personality of middle education. Pedagogy. No5. Pp.16 -21.

[11] Kirjakova A.V. (2011) Axiological paradigm of modern University education. Vysshee obrazovanie segodnja. No 1. Pp.19-21.

[12] Krysin L.P, Diligenskij G.G. (2001) [Economic-language-culture (discussion)]. Obshhestvenne nauki I sovremennost. No. 5. Pp. 48 - 57.

[13] Klepcova E. (2008) Child intolerance. Doshkol'noe vospitanie. No. 7. Pp .78-81. 